\title{
APPROBATION OF PHYSIOTHERAPETIC METHOD IN LUMBOSACRAL PAIN SYNDROME
}

\author{
Stamenka Mitova ${ }^{1}$, Mariya Gramatikova ${ }^{1}$, Gergana Nenova ${ }^{2}$, Stanislava \\ Bogomilova $^{2}$ \\ 1) Department of Kinesitherapy, Faculty of Public Health, Healthcare and \\ Sports, South-West University "Neofit Rilski", Blagoevgrad, Bulgaria \\ 2) Department of Kinesitherapy, Faculty of Public Health, Medical University, \\ Varna, Bulgaria.
}

\section{SUMMARY}

The aim of this study was to approbate own kinesitherapeutic methodology in lumbosacral pain syndrome and to study its effectiveness.

Material and Methods: The study includes 36 participants, mean age $(\bar{X} \pm$ SD) $51.67 \pm 4.93$ years, selected according to the indications for the use of experimental methods. The methodology includes the following functional tests: anamnesis, somatoscopy, Shober Test, Ott Test, Lasseg Test, VAS (Visual Analog Scale). The examination of the pain was done through experimentally induced palpation pain (applying the same pressure, by the same person) in trigger point (TP) and evaluated with VAS. Values of pain were measured before therapy and tree months after kinesitherapy treatment which includes: soft-tissue mobilization, analytical exercises, post-isometric relaxation, hydrotherapy (tangentor).

Results: 36 people (12 women and 24 men) with lumbosacral pain syndrome were included. The mean $( \pm$ $\mathrm{SD})$ of the pain threshold measured before and three months after the kinesitherapy program was $9.06 \pm$ $0.79 \mathrm{~mm}$ and $1.69 \pm 0.82 \mathrm{~mm}$, respectively. Differences in mean pain thresholds in both measurement period were statistically significant ( $\mathrm{p}<0.05)$.

Conclusions: Data presented demonstrate the effectiveness and positive effects of the applied kinesitherapeutic methodology in patients with lumbosacral pain syndrome. The strong reduction in pain symptom and muscle spasm in the course of three months treatment improves the quality of life of patients with this pathology.

Keywords: rehabilitation, dysfunctions, spine, research, prevention, treatment,

\section{INTRODUCTION}

Back pain is a significant medical and social problem in developed countries. The prevalence of pain in the lower back is $84 \%$, and chronic low back pain is about $23 \%$, such as $11-12 \%$ of the population has a disability of back pain [1].

The lumbar spine is a well-designed structure of connecting bones, joints, nerves, tendons and muscles that work together to provide support, strength and flexibility. However, this complex structure of the lower back is susceptible to pain and dysfunctions. Pain in the lumbar spine is among the most common cause of dysfunctions with the greatest social and economic importance, according to WHO.

Traditionally, the pain can be represented by three major pathophysiological components: nociceptive, neuropathic and psychogenic. Nociceptive back pain is associated with the activation of pain receptors - nociceptors. The role of peripheral nociceptive pain sources is relatively well studied and it's the most common cause of back pain and musculoskeletal disorders. Spondyloarthropathic pain syndrome is one of the most common conditions associated with the formation of nociceptive pain. The pain, which is a direct consequence of disease or damage to the somatosensory system, is neuropathic. It is usually associated with nerve root damage during hernia formation. Psychogenic back pain is extremely difficult to diagnose $[2,3]$.

Lambalgia is often a benign and treatable disease, especially when the intervention is on time and adequate. Pain can be avoided if the lumbar spine region, like all other organs in the human body, requires attention and care. The tendency to the recurrence of pain in the lumbar spine still requires the use of kinesitherapeutic methods. Proper management leads to improved health status and hence the quality of life of these patients. The teamwork of the kinesitherapist, general practitioner, and other physicians, besides improving the general physical condition of the patient, also affects his / her psychosomatic condition. Improvement of locomotors activity and efficiency increase self-confidence and the adaptation of the patient to the environment $[5,6,7,8]$.

\section{MATERIAL AND METHODS}

A contingent in this study was 36 patients mean aged $( \pm \mathrm{SD})$ of $51.67 \pm 4.93$ years. Our inclusion criteria in the program were low back pain for at least six weeks; without leg pain or neurological signs. We excluded patients with serious diseases, including systemic rheumatic pathologies, gynecological problems, ankylosing spond- 
ylitis, tumors, infection, previous spine surgery. We excluded patients aimed at programs for intensive functional restoration. Functional tests and kinesitherapeutic procedures were performed after informed written consent of the investigated.

The methodology includes the following functional tests: anamnesis (physical exercise data, motor behavior), somatoscopy (view), Shober Test, Ott Test, Lasseg Test, VAS (Visual Analog Scale). The examination of the pain was done through experimentally induced palpation pain (applying the same pressure, by the same person) in trigger point (TP) and evaluated with VAS. Values of pain were measured before therapy and tree months after kinesitherapy treatment, which includes soft-tissue mobilization, analytical exercises, post-isometric relaxation, specific exercises (McKenzie), general exercises for the mobility of the lumbar spine, hydrotherapy (tangentor).

VAS is a scale to evaluate pain perception with a length of $100 \mathrm{~mm}$. The left end of the scale reflects a „no pain” level, and the right one - ,, a very strong pain”. After palpation in TT, the patient indicates the point on the scale that he thinks reflects the strength of his pain perception at the time of measurement. The intensity of pain is recorded as the length in millimeters, measured from the left end of the scale to the point indicated by the patient. The results were processed statistically with variation analysis and Prism tests.

\section{RESULTS}

36 patients ( 12 women and 24 men) were included (Figure 1), the mean age of the observed contingent $( \pm$ SD) in females was $48.17 \pm 4.82 \mathrm{~g}$, and in males, $53.42 \pm$ $4.04 \mathrm{~g}$, the mean values of height and weight (Figure 2) are as follows for women: $166.9 \pm 3.06 \mathrm{~cm}$ and $71.58 \pm$ $6.53 \mathrm{~kg}$, in males $174.3 \pm 3.39 \mathrm{~cm}$ and $101.0 \pm 6.87 \mathrm{~kg}$.

Fig. 1. Distribution of research contingent

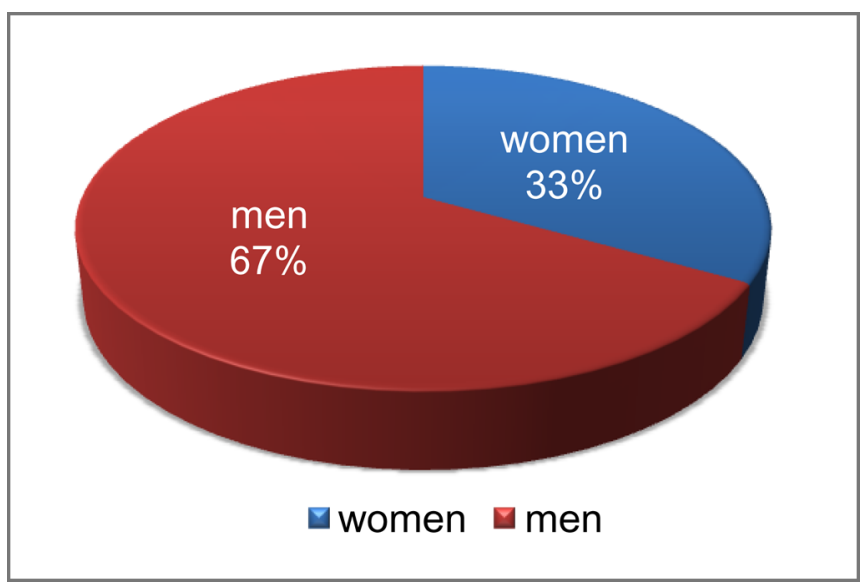

Fig. 2. Distribution of research contingent on gender age

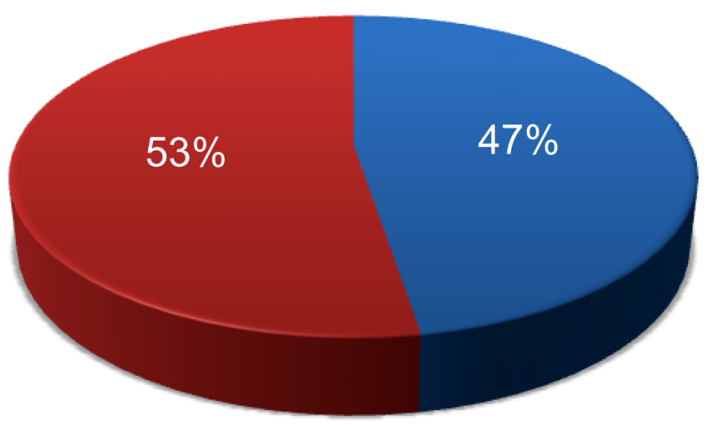

$\square$ women $\square$ men

The mean values $( \pm$ SD) of the Ott and Shober test (Figure 3) examined before and after applied kinesitherapeutic method were as follows: $2.47 \pm 0.45 \mathrm{~cm}$ and $4.21 \pm 0.54 \mathrm{~cm}$ for the Ott test and $1.61 \pm 0.43 \mathrm{~cm}, 2.94 \pm$ $0.72 \mathrm{~cm}$ for the Shober test. Lasseg test (Figure 4) averaged values before KT $67.78 \pm 4.22^{\circ}$ and $82.08 \pm 4.03^{\circ}$ after CT.

Fig. 3. Average values of spine mobility

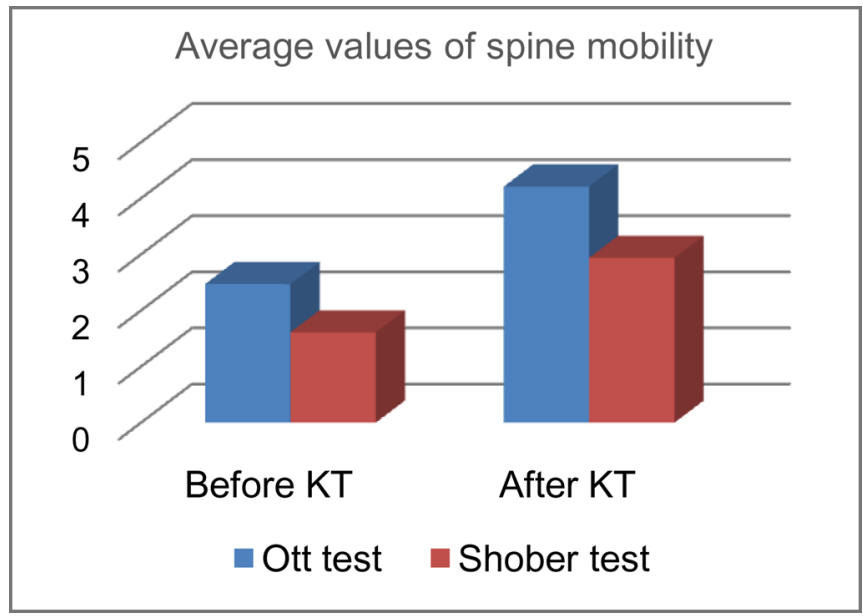

Fig. 4. Average values of the range of motion

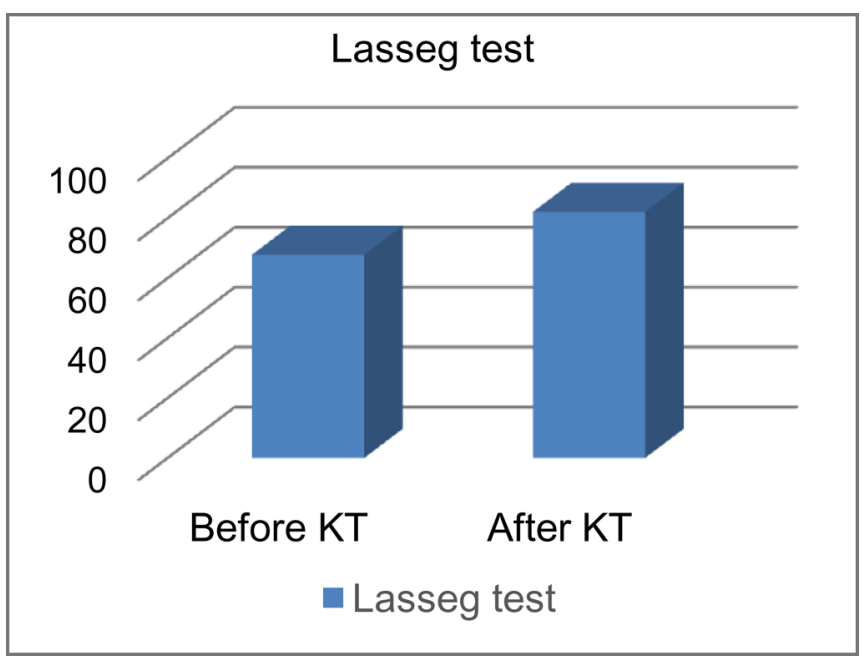


The pain threshold values measured before and three months after the kinesitherapy program were $9.06 \pm 0.79 \mathrm{~mm}$ and $1.69 \pm 0.82 \mathrm{~mm}$, respectively (Table 1). Differences in pain threshold values in the two measurement periods were statistically reliable $(\mathrm{p}<0.05)$.

Table 1. The pain threshold values measured before and after the KT program

\begin{tabular}{|l|c|c|c|c|c|c|}
\hline $\begin{array}{l}\text { VAS } \\
\text { N=36 }\end{array}$ & $\boldsymbol{X}$ & St. Deviation & $\boldsymbol{X}$ max. & $\boldsymbol{X}$ min. & Std. Error & V \% \\
\hline Before KT & 9.16 & 0.77 & 10.00 & 8.00 & 0.14 & $8.37 \%$ \\
\hline After KT & 1.72 & 0.77 & 4.00 & 1.00 & 0.13 & $45.63 \%$ \\
\hline
\end{tabular}

\section{DISCUSSION}

The main objective of the present study was to approve the author's kinesitherapeutic method and to study its effectiveness as well as to improve the general condition of patients with lumbosacral pain syndrome. The methodology was focused on influencing in a positive adaptation and quality of life; adequate treatment of chronic pain; developing a proper strategy and individual approach for every patient; regular reviews of a general practitioner and a neurologist. Manual soft-tissue mobilization combined with analytical exercises, post-isometric relaxation, specific exercises (McKenzie), general lumbar spine mobility exercises and hydrotherapy (tangentor) affects muscle tone. In addition, has a trophic effect for reflexively inhibited muscles and relaxing for shortened, hypertensive muscles decreases the number of pain points and the intensity of pain.

The results prove that the targeted application of specially developed exercise complexes helps to improve health, increase the mobility of the spine and reduce the pain threshold.
Lumbosacral pain syndrome is one of the most common complaints and reason for a doctor's visit. Over $10 \%$ of visits to a primary care physician refer to back pain [8].

\section{CONCLUSION}

In conclusion, we can say that the implementation of specially selected exercises leads to the improvement of the condition of persons with lumbosacral pain syndrome. Data presented to demonstrate the efficacy and positive effect of the applied kinesitherapeutic method in patients with lumbosacral pain syndrome. The strong reduction in pain symptom and muscle spasm in the course of three months treatment improves the quality of life of patients with this pathology.

\section{Acknowledgements:}

This article is supported under Project No. RP-A1/ 19, Project topic: Research The Possibilities Of Laser Acupuncture For Muculoskeletal Dysfunctions In The Spinal Column Region.

\section{REFERENCES:}

1. Balague F, Mannion AF, Pellise F, Cedraschi C. Non-specific low back pain. Lancet. 2012 Feb 4;379(9814): 482-91. [PubMed]

2. Podchufarova EB. [Chronic back pain: current understanding of the mechanisms of development and treatment]. First Moscow State Medical University named after I.M. Sechenova. 2012; 4(39). [in Russian]

3.Wáng YXJ, Wu A-M, Santiago FR, Nogueira-Barbosa MH. Informed appropriate imaging for low back pain management: A narrative review. J Orthop Translat. 2018 Aug 27;15: 21-34. [PubMed]
4. Goudman L, Huysmans E, Ickmans K, Nijs J, Moens M, Putman K, et al. A Modern Pain Neuroscience Approach in Patients Undergoing Surgery for Lumbar Radiculopathy: A Clinical Perspective. Phys Ther. 2019 Jul 1;99(7):933-945. [PubMed]

5. Halonen JI, Shiri R, Magnusson Hanson LL, Lallukka T. Risk and Prognostic Factors of Low Back Pain: Repeated Population-based Cohort Study in Sweden. Spine (Phila Pa 1976). 2019 Sep 1;44(17):12481255. [PubMed]

6. Kurganova UM, Danailov AB.
[Melatonin for back pain and predictors of its effectiveness.] Journal of Neurology and Psychiatry. 2017; 117(10):49-54. [in Russian]

7. Parashkevova P, Deleva R, Mincheva P, Andreev A. A Study on Use of Neurodynamic Tests among Neurorehabilitation Professionals. J of IMAB. 2019 Jan-Mar;25(1):24382442. [Crossref].

8. Mafi JN, McCarthy EP, Davis $\mathrm{RB}$, Landon BE. Worsening trends in the management and treatment of back pain. JAMA Intern Med. 2013 Sep 23;173(17):1573-81. [PubMed] 
Please cite this article as: Mitova S, Gramatikova M, Nenova G, Bogomilova S. Approbation of Physiotherapetic Method in Lumbosacral Pain Syndrome. J of IMAB. 2020 Oct-Dec;26(4):3432-3435.

DOI: https://doi.org/10.5272/jimab.2020264.3432

Received: 24/09/2019; Published online: 13/11/2020

(c) ()

Address for correspondence:

Assoc. Prof. Stamenka Mitova, PhD

Department of Kinesitherapy, Faculty of Public Health, Healthcare and Sports, South-West University „Neofit Rilski“

66, Ivan Mihaylov Str., 2700 Blagoevgrad, Bulgaria

E-mail: stami80@abv.bg 